\title{
A survivor population of wild colonies of European honeybees in the northeastern United States: investigating its genetic structure
}

\author{
Thomas D. SeEley ${ }^{1}$, David R. TARPY ${ }^{2}$, Sean R. Griffin ${ }^{1,3}$, Angela CARCIONE ${ }^{4}$, \\ Deborah A. DelaneY ${ }^{4}$ \\ ${ }^{1}$ Department of Neurobiology and Behavior, Cornell University, Ithaca, NY 14853, USA \\ ${ }^{2}$ Department of Entomology and W. M. Keck Center for Behavioral Biology, North Carolina State University, Raleigh, \\ NC 27696, USA \\ ${ }^{3}$ Department of Ecology, Evolution, and Natural Resources, Rutgers University, New Brunswick, NJ 08901, USA \\ ${ }^{4}$ Department of Entomology and Wildlife Ecology, University of Delaware, Newark, DE 19716, USA
}

Received 18 July 2014 - Revised 17 December 2014 - Accepted 5 February 2015

\begin{abstract}
There is a widespread belief that wild colonies of European honeybees have been eradicated in Europe and North America, killed by viruses spread by the introduced ectoparasitic mite, Varroa destructor. In reality, however, several populations of wild colonies of honeybees in Europe and North America are persisting despite exposure to Varroa. To help understand how this is happening, we tested whether the bees in one of these populations of wild colonies - those living in and around the Arnot Forest (NY, USA) - are genetically distinct from the bees in the nearest managed colonies. We found that the Arnot Forest honeybees are genetically distinct from the honeybees in the two apiaries within $6 \mathrm{~km}$ of the forest. Evidently, the population of Arnot Forest honeybees is not supported by a heavy influx of swarms from the nearest managed colonies, which implies that it is self-sustaining. These results suggest that if a closed population of honeybee colonies is allowed to live naturally, it will develop a balanced relationship with its agents of disease. Indeed, it is likely to become well adapted to its local environment as a whole. We suggest four ways to modify beekeeping practices to help honeybees live in greater health.
\end{abstract}

host-parasite coevolution / avirulence / survivor population / wild honeybees / Arnot Forest

\section{INTRODUCTION}

It is commonly believed that self-sustaining populations of wild colonies of European honeybees no longer exist in Europe and North America and that any wild colonies of European honeybees still found in these regions come from swarms that have escaped from beekeepers' hives (Moritz et al. 2007; Potts et al. 2010). One reason for this

Corresponding author: T. Seeley, tds5@cornell.edu

Manuscript editor: Yves Le Conte belief is that many parts of Europe have experienced extensive forest clearing to produce agricultural land, so there remain few old trees with large cavities - the natural nest sites of honeybees (Oleksa et al. 2013). Even in forested nature preserves in Europe, where nesting cavities for honeybees must be plentiful, recent studies have shown that the total density of colonies appears to match the density of managed colonies (Moritz et al. 2007; Jaffé et al. 2009). This suggests that wild colonies of honeybees are rare even in these natural areas. Presumably, this is due to parasites and pathogens, especially Varroa destructor and associated viruses. Multiple studies have shown 
that if a managed colony of European honeybees in Europe or North America is not treated for $V$. destructor, then in a year or two the population of mites infesting it will explode and the colony will die (Korpela et al. 1992; Kraus and Page 1995a; Fries et al. 2006).

It is reasonable to expect, therefore, that populations of honeybee colonies that are living in the wild, and so are not receiving mite-control treatments, have died out. This expectation seems to be supported by a study of wild colonies of European honeybees in central California conducted in 1990-1994, shortly after the arrival of $V$. destructor, which found that this population of colonies was nearly eradicated (Kraus and Page 1995b). Likewise, a population of wild colonies of European honeybees in Arizona was decimated between 1990 and 1998 when it was invaded first by tracheal mites (Acarapis woodi) and then by $V$. destructor (Loper et al. 2006). Furthermore, a study in Louisiana conducted in 1991-2006 found a steep drop in capture rate of swarms and in longevity of these swarms shortly after the arrival of $V$. destructor in 1993 (Villa et al. 2008).

Recently, however, several reports have emerged from Europe and North America of populations of wild colonies of European honeybees that have persisted for at least 10 years despite being infested with $V$. destructor: Sweden (Fries et al. 2006), France (Le Conte et al. 2007), and the USA (Seeley 2007). There is also the fact that European honeybees have co-existed with Varroa mites in far-eastern Russia since the mid-1800s (Rinderer et al. 2001). The evolution of a balanced host-parasite relationship between honeybees and their parasites is actually expected where most colonies are living in the wild, for in this ecological setting, there should be strong natural selection for bees possessing resistance to diseases. Also, because honeybee colonies living in the wild in Europe and North America are spaced widely (Galton 1971; Seeley 2007), there may be little movement of bees between colonies, so there may be little horizontal transmission of pathogens and parasites among wild colonies. If vertical (from parent to offspring) transmission of disease agents is the rule among wild colonies of honeybees, then there should be selection for avirulence in the pathogens and parasites that live in these colonies (Fries and Camazine 2001; Schmid-Hempel 2011).

One population of wild colonies of European honeybees that is persisting despite infestations of $V$. destructor lives in (and around) the Arnot Forest in central New York State. The first survey of the colonies living in this research preserve was made in 1978 (Visscher and Seeley 1982), more than 10 years before the arrival of $V$. destructor in New York State, and a second survey was made in 2002 (Seeley 2007), some 10 years after the arrival of these mites in the region. Surprisingly, the two surveys yielded essentially identical estimates of the number of colonies living in the forest: 1978, 18 colonies; 2002, 16 colonies (see below). In 2003, the Arnot Forest colonies were tested for infestation with $V$. destructor by trapping swarms in the forest with bait hives and then inspecting the captured colonies for mites. All were infested with $V$. destructor, but their mite populations did not grow to high levels in late summer (Seeley 2007). Studies of the $V$. destructor population dynamics in the wild honeybee colonies in Sweden (Gotland) and France (Avignon) have also found low rates of mite population growth and correspondingly low mite loads (Fries et al. 2006; Le Conte et al. 2007).

Populations of wild European honeybee colonies surviving in Europe and North America are important because understanding the genetic and ecological factors that enable them to persist could reveal novel resistance mechanisms for future bee breeding programs and could suggest beneficial changes in beekeeping practices. A critical first step toward exploring these possibilities is to determine whether any given population of wild honeybee colonies is truly selfsustaining or is simply persisting through immigration of swarms that have escaped from managed honeybee colonies. We have addressed this question for the Arnot Forest honeybees by determining whether the wild colonies living in and around this forest are genetically distinct from the nearest managed colonies living outside this forest. If so, then this will be strong evidence that this population is truly surviving on its own. 


\section{MATERIALS AND METHODS}

\subsection{Study site}

We conducted our study within the circular, $200-\mathrm{km}^{2}$ (radius $8.0 \mathrm{~km}$ ) area of countryside that is centered on the Arnot Forest, a $17-\mathrm{km}^{2}$ research preserve owned by Cornell University. This large study area is located in a rugged, high-elevation (310-620 m) region of southern Tompkins County and northern Chemung and Schuyler Counties, NY, USA (42 $\left.12^{\circ} \mathrm{N}, 76^{\circ} 39^{\prime} \mathrm{W}\right)$ (see Figure 1). It is mostly forested ( $82 \%$, based on GIS analysis) and sparsely settled (2.30 houses/ $\mathrm{km}^{2}$, based on US Geological Survey maps). The vegetative cover of the Arnot Forest is mainly (96\%) forest that ranges from old-field successional forest to mature hardwood and softwood forests (see Fig. 3 in Odell et al. 1980). The land surrounding the Arnot Forest, which includes the adjoining Newfield and Cliffside State Forests, is similarly forested, having been protected by New York State, or abandoned from agriculture (or both), over the past 100 years.

\subsection{Sampling worker bees from wild and managed colonies}

In July and August 2011, we located the wild colonies of honeybees living in the northeastern, central, and southeastern regions of the Arnot Forest using the technique of bee-lining (Visscher and Seeley 1989). We started each search for a colony by capturing in a "bee box" approximately 10 worker bees from flowers in a single forest clearing, giving the captured bees scented sugar syrup $(2.0 \mathrm{~mol} / \mathrm{L})$ in a comb placed inside the bee box, and then releasing the bees after they had loaded up on the sugar syrup. After flying home, some of the bees returned to the box to collect more food, and then some of these bees recruited additional bees to our rich food source. Next, we labeled (with individually identifiable paint marks) $10-20$ of the bees visiting the comb, at which point, we began measuring their vanishing bearings and their round-trip times, to estimate the direction and distance to their nest. Once we had this information, we trapped approximately 10 of the bees inside the bee box, moved everything 100-200 $\mathrm{m}$ to another clearing in the direction of the bees' nest, and released the bees so they could continue foraging at the bee box, but now at the new site. We thus worked our way, step-by-step, back to the bees' nest site. When we got close and had hundreds of bees from the colony excitedly visiting the bee box, we collected a sample of approximately 100 bees (all workers) in $95 \%$ ethanol. We are confident that we located most, if not all, of the colonies in the regions of the Arnot Forest that we surveyed, because eventually the beelines that we started from several dozen clearings in these regions pointed consistently to colonies that we had already located. Figure 2 in Seeley (2007) depicts this process of saturation sampling.

In July and August 2011, we also searched for managed honeybee colonies living outside the Arnot Forest but within the $200-\mathrm{km}^{2}$ study area, hence within a band approximately $6 \mathrm{~km}$ wide surrounding the Arnot Forest. We restricted our search to this region because swarms rarely disperse more than $3 \mathrm{~km}$ (Lindauer 1955; Seeley and Morse 1977) and drones rarely fly more than $6 \mathrm{~km}$ to mate with a queen (Ruttner and Ruttner 1966, 1972), so it is unlikely that there has been strong maternal (via swarms) or paternal (via drones) gene flow into the Arnot Forest from managed colonies located more than $6 \mathrm{~km}$ away. We searched for managed colonies in four ways: (1) We contacted the local beekeeping club (Finger Lakes Beekeepers), (2) we talked to the two commercial beekeepers based within $30 \mathrm{~km}$ of the Arnot Forest (Tremblay Apiaries, Spencer, NY, and Beeman Apiaries, Owego, NY), (3) we drove slowly down all the roads within $6 \mathrm{~km}$ of the Arnot Forest, and (4) we studied aerial photographs (Google Earth). We found only two apiaries (hereafter, referred to as apiary 1 and apiary 2), both belonging to one beekeeper. We collected a sample of approximately 100 bees, stored in $95 \%$ ethanol, from each of 10 colonies in both apiaries, which contained 22 and 24 colonies. Because we searched thoroughly for apiaries within our 200$\mathrm{km}^{2}$ study area, using four different methods, we are confident that the two apiaries found were the only ones present within the study area.

\subsection{DNA analyses}

\subsubsection{DNA extraction}

We made separate DNA extracts of four worker bees from each of the 10 colonies in each group 


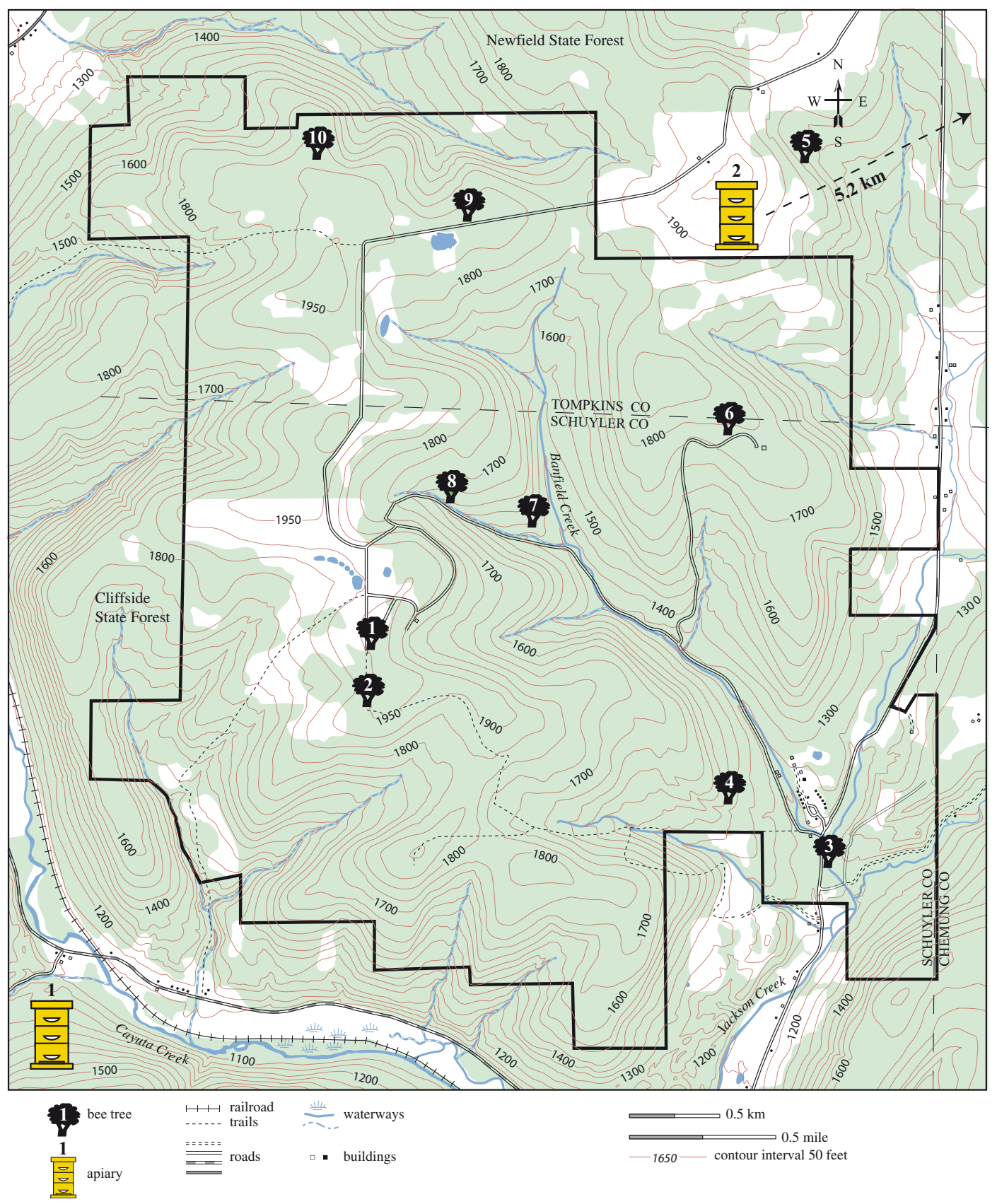

Figure 1. Map of the Arnot Forest and surrounding land. It shows the locations of the 10 wild colonies of honeybees (bee trees) and the two clusters of managed colonies of honeybees (apiaries) closest to the forest. Green areas denote forest; white areas denote old fields that are reverting to forest (Color figure online).

(Arnot Forest, apiary 1, and apiary 2), hence 40 bees total for each group and 120 bees overall. Each bee's hind legs were cut off, placed in a microcentrifuge tube, subjected to a series of buffers, and run through centrifuge regimens to lyse the cells and release the DNA (protocol for Qiagen DNeasy Blood and Tissue Kit). Each extract was stored at $-80{ }^{\circ} \mathrm{C}$. 

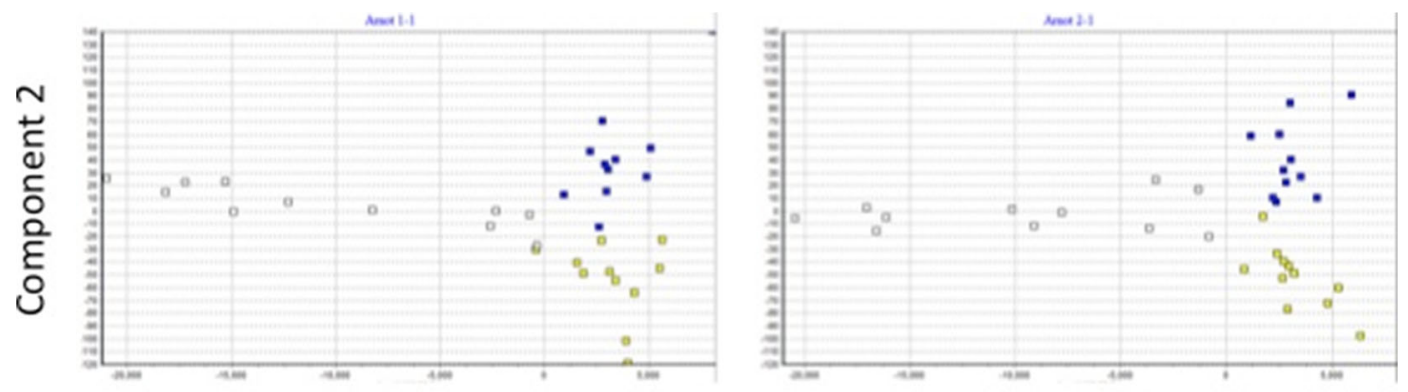

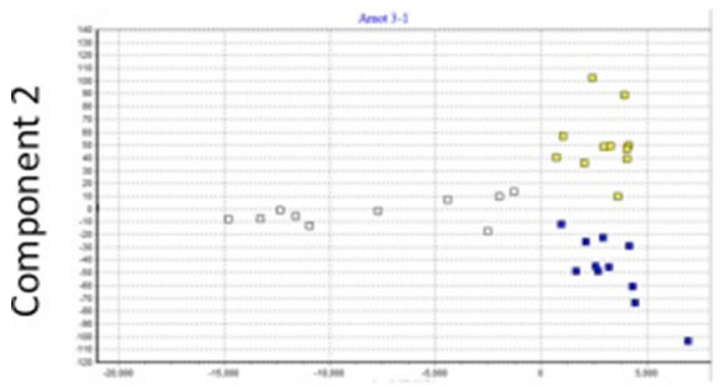

Component 1

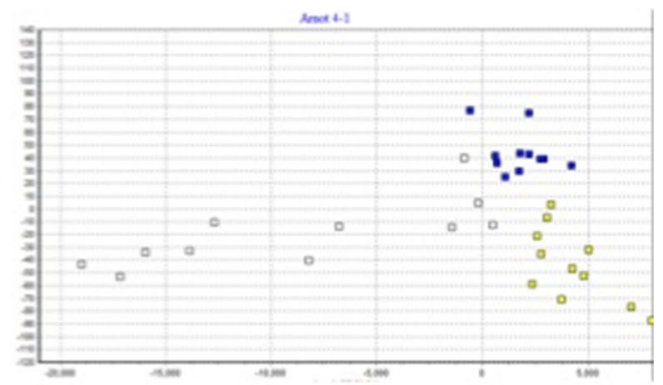

Component 1

Figure 2. Two-dimensional representations of the results of four independent factorial correspondence analyses, each of which was based on the allele frequencies of 12 variable microsatellites for 10 individuals in each of the three groups: Arnot Forest (yellow), apiary 1 (blue), and apiary 2 (white) (Color figure online).

\subsubsection{Microsatellites}

We subjected the four DNA extracts from each colony to PCR at 12 variable microsatellite loci: A24, A28, A79, A88, A107, Ap43, Ap66, Ap81, AC006, B124 (Estoup et al. 1995; Garnery et al. 1992; Solignac et al. 2003), and HB-THE-03 and HB-THE-04 (Shaibi et al. 2008), using the previously reported reaction conditions. The final reaction volume per sample was $\sim 10 \mu \mathrm{L}$ and contained $5 \mu \mathrm{L}$ of PCR Master Mix (Promega, Madison, WI), 1.0 $2.5 \mu \mathrm{L}$ of fluorescent dye-labeled primer, $0.9 \mu \mathrm{L}$ of nuclease-free water, and $2 \mu \mathrm{L}$ of DNA extract. Each extract was amplified for one cycle at $95^{\circ} \mathrm{C}$ for $7 \mathrm{~min}$; then 30 cycles of $95^{\circ} \mathrm{C}$ for $30 \mathrm{~s}, 54^{\circ} \mathrm{C}$ for $30 \mathrm{~s}$, and $72^{\circ} \mathrm{C}$ for $30 \mathrm{~s}$; and finally an extension at $72{ }^{\circ} \mathrm{C}$ for $60 \mathrm{~min}$. We ran the amplification on an Applied Biosystems 3730 automatic sequencer and we scored the microsatellite fragment sizes using GeneMapper.

\subsubsection{Genetic profiles}

Using a variety of analytic software, we made four independent analyses of each group of bees (Arnot
Forest, apiary 1, and apiary 2); each analysis was based on the genetic profiles of 10 different bees (out of the 40 bees processed per group) in each group. First, we used HP-Rare (Kalinowski 2005) to calculate the average number of alleles per locus, number of private alleles, allelic richness, and expected heterozygosity. Second, we used GENEPOP version 4.0 (Raymond and Rousset 1995; Rousset 2008) to look for departures from Hardy-Weinberg equilibrium, genotypic linkage disequilibrium, and genic differentiation. Third, we used GENETIX version 4.04 (Belkhir et al. 2002) to make a factorial correspondence analysis. Finally, we determined the allele frequencies and singlelocus frequencies for each group using GENETIX, and we used FSTAT (Goudet 2001) to make four estimates of the $\mathrm{F}_{\mathrm{st}}$ for each pair of groups.

\subsubsection{Mitochondrial DNA}

We used the same DNA extracts from each colony to determine its maternal ancestry. The intergenic region between the COI and COII gene of the mitochondrial DNA was amplified using PCR and the primers E2 (5'- 
GGCAGAATA-AGTGCATTG-3') and H2 (5'-CAAT ATCATTGAT-GACC-3') following the protocol developed by Garnery et al. (1992). Each sample's reaction volume was $25 \mu \mathrm{L}$ and contained $12.5 \mu \mathrm{L}$ of PCR Master Mix (Promega, Madison, WI), $5 \mu \mathrm{L}$ of water containing 25 pmol of both E2 and $\mathrm{H} 2$ primers, $5.5 \mu \mathrm{L}$ of distilled water, and $2 \mu \mathrm{L}$ of DNA extract. We amplified all extracts for 30 cycles of $30 \mathrm{~s}$ at $92^{\circ} \mathrm{C}, 1.5 \mathrm{~min}$ at $47{ }^{\circ} \mathrm{C}$, and $2 \mathrm{~min}$ at $63{ }^{\circ} \mathrm{C}$. The PCR product for each extract was purified (Qiagen ${ }^{\circledR}$ MinElute Purification Kit) and the purified amplicon was sequenced using an Applied Biosystems 3730 automatic sequencer. We used the program FinchTV (Geospiza, Seattle, WA) to view and edit the DNA chromatograms and we used the Basic Local Alignment Search Tool (BLAST) to align sequences in GeneBank to determine the evolutionary lineage of each colony. We uploaded sequence files of fragment sizes to GenBank and determined the closest mtDNA haplotype names (97-99 \% match) within honeybee mitochondrial lineages.

\subsubsection{Statistical analysis}

For each pair of our three groups (Arnot Forest/ apiary 1, Arnot Forest/apiary 2, and apiary 1/apiary 2), we made four independent estimates of $\mathrm{F}_{\mathrm{st}}$. Each estimate of $F_{\text {st }}$ for a given pair was based on data obtained from 10 worker bees ( 1 bee per colony) from the sample of 40 bees that we analyzed for each group. We used our four estimates of the multilocus $F_{\text {st }}$ for each pair of groups to calculate the mean and standard deviation of our estimates of $\mathrm{F}_{\mathrm{st}}$ for each pair of groups. We then determined the probability that the actual $\mathrm{F}_{\mathrm{st}}$ could be 0.00 , using a Student's $t$ distribution for $n=4$.

\section{RESULTS}

\subsection{Wild and managed honeybee colonies}

Our mapping of the wild colonies in the Arnot Forest covered approximately $50 \%$ of its area and revealed 10 colonies, 9 inside its boundaries and 1 just outside (Figure 1). Table I summarizes our estimates of the number and density of wild colonies living in the Arnot Forest, based on present and past surveys.

Our search for managed colonies outside the Arnot Forest revealed just two apiaries, both owned by Tremblay Apiaries. Apiary 1 was
$1.0 \mathrm{~km}$ from the southwest boundary of the Arnot Forest (Figure 1). This was a new apiary established in April 2011 with 22 colonies. Each colony had been given a new queen purchased from Wooten's Golden Queens, Palo Cedro, California. All 22 queens had mated in California in the spring of 2011. Apiary 2 was $5.2 \mathrm{~km}$ from the northeast boundary of the Arnot Forest. This apiary had been in existence since 2001 and contained 24 colonies. From time to time, some of the colonies were requeened using queens that were either purchased from various commercial queen producers or produced by the beekeeper using his own stock.

\subsection{DNA analyses}

\subsubsection{Genetic diversity}

The average number of alleles per locus varied from 3.68 \pm 1.47 (Arnot Forest) to 3.02 \pm 1.32 (apiary 1) and $3.08 \pm 1.31$ (apiary 2). The average gene diversity, measured as expected heterozygosity, was similar for the three groups of colonies: 0.63 \pm 0.22 for the Arnot Forest colonies and $0.57 \pm 0.12$ and $0.58 \pm 0.24$ for the apiary 1 and apiary 2 colonies, respectively.

\subsubsection{Hardy-Weinberg equilibrium}

The exact test for Hardy-Weinberg equilibrium (HWE) found all three groups (Arnot Forest, apiary 1 , and apiary 2 ) significantly deviated from HWE $\left(X^{2} \infty, P \sim 0\right)$. Further analysis revealed that in the Arnot Forest group, 2 of the 12 loci deviated significantly from HWE, with a significant deficit $(P<0.001)$ of heterzygotes at the locus HB-THE03 and a significant excess $(P<0.001)$ of homozygotes at the locus Ap43. In the apiary 1 group, 3 of the 12 loci deviated from HWE (A79, AC006, and HB-THE-04). All three had a significant deficit of heterozygotes $(P<0.005,0.001$, and 0.04 , respectively). In the apiary 2 group, 5 of the 12 loci deviated significantly from HWE (A24, A79, A107, Ap81, and B124) $(P<0.001,0.001,0.001$, 0.029 , and 0.007 , respectively), with significant deficits of heterozygotes at the loci A79 and 
Table I. The number of wild honeybee colonies found in the 17- $\mathrm{km}^{2}$ Arnot Forest, for three surveys made in 1978 (Visscher and Seeley 1982), 2002 (Seeley 2007), and 2011 (this study).

\begin{tabular}{lllll}
\hline Year & $\begin{array}{l}\text { No. of colonies } \\
\text { found }\end{array}$ & $\begin{array}{l}\text { \% of forest } \\
\text { surveyed }\end{array}$ & $\begin{array}{l}\text { Estimate of total } \\
\text { colony number }\end{array}$ & $\begin{array}{l}\text { Estimate of colony density } \\
\left(\text { colonies } / \mathrm{km}^{2}\right)\end{array}$ \\
\hline 1978 & 9 & 50 & 18 & 1.06 \\
2002 & 8 & 50 & 16 & 0.94 \\
2011 & 9 & 50 & 18 & 1.06 \\
\hline
\end{tabular}

Also shown are estimates of the total number of colonies and the density of colonies in this forest

A107, and a significant excess of heterozygotes at the other three loci.

\subsubsection{Genetic differentiation}

The genetic differentiation test indicated that differences existed between the Arnot Forest and apiary 1 colonies at 11 of the 12 loci, and between the Arnot Forest and apiary 2 colonies at all 12 loci, but at only 6 of the 12 loci between the apiary 1 and apiary 2 colonies. The values of average allelic richness and average number of private alleles per locus for each group of colonies are shown in Table II. The Arnot Forest colonies had a markedly higher average number of private alleles per locus than the apiary 1 and apiary 2 colonies ( $2.85 \pm 1.83$ vs. $0.83 \pm 0.78$ and $0.68 \pm 0.63)$, with more private alleles at 10 of 12 loci. The analysis for linkage disequilibrium revealed only 2 of 66 pairwise comparisons across all groups to be significant $(P=0.05)$. This general lack of linkage disequilibrium across pairwise comparisons suggests that no significant linkage disequilibrium occurred between pairs of loci.1x(^Xin_styles)tgroupX

The four independent sets of pairwise multilocus $F_{\text {st }}$ estimates revealed that the Arnot Forest colonies were significantly different (or nearly so) from the colonies in apiary 1 $(P<0.01)$ and apiary $2(P<0.07)$, with $\mathrm{F}_{\text {st }}$ values ranging from 0.016 to 0.027 for the Arnot Forest-apiary 1 comparison and from 0.022 to 0.069 for the Arnot Forest-Apiary 2 comparison (see Table III). Evidently, there has been little gene flow between the Arnot Forest colonies and the colonies in the two apiaries. Likewise, the $\mathrm{F}_{\text {st }}$ values for the apiary 1-apiary 2 comparison range from 0.053 to 0.099 and indicate that the colonies in these apiaries also have significantly different $(P<0.04)$ genetic backgrounds, which is to be expected given that the queens in the apiary 1 colonies all came from one commercial queen producer but those in the apiary 2 colonies came from various sources.

The results of the FCA analyses, shown in Figure 2, are further evidence of genetic differentiation between the three groups of colonies. In all four analyses, there is almost no genetic overlap between the wild colonies in the Arnot Forest and the managed colonies in apiary 1 or apiary 2 , or between the colonies in these two apiaries.

\subsubsection{Mitochondrial DNA}

Sequencing of the COI-COII intergenic region revealed just two haplotypes in the three groups of colonies: $\mathrm{C} 1$ and $\mathrm{C} 2$, which are common in two subspecies of the honeybee native to Europe, Apis mellifera ligustica and Apis mellifera carnica, respectively. The 8 colonies in the Arnot Forest that yielded a clear result exhibited an even distribution of the $\mathrm{C} 1$ (ligustica) and C2 (carnica) haplotypes (50\% $\mathrm{C} 1$ and $50 \% \mathrm{C} 2$ ); however, the 10 colonies in both apiary 1 and apiary 2 exhibited mainly the C2 (carnica) haplotype (90 and $80 \% \mathrm{C} 2$, respectively). The closest mtDNA haplotype names (97-99\% match) from the sequences uploaded into GeneBank are as follows: Arnot Forest, $\mathrm{C} 1 \mathrm{a}, \mathrm{C} 2 \mathrm{j}$, and $\mathrm{C} 2 \mathrm{~s}$; apiary $1, \mathrm{C} 1 \mathrm{a}$ and $\mathrm{C} 2 \mathrm{j}$; and apiary $2, \mathrm{C} 1 \mathrm{a}$ and $\mathrm{C} 2 \mathrm{j}$. 
Table II. Number of different alleles per locus (allelic richness) and number of private alleles per locus for each group of colonies. Allelic richness values were calculated using the statistical technique of rarefaction to compensate for small sample size.

\begin{tabular}{|c|c|c|c|}
\hline & Arnot Forest & Apiary 1 & Apiary 2 \\
\hline \multicolumn{4}{|l|}{ Locus A24 } \\
\hline Allelic richness & 3.6 & 3.0 & 3.6 \\
\hline Private alleles & 0.6 & 0.3 & 1.0 \\
\hline \multicolumn{4}{|l|}{ Locus A28 } \\
\hline Allelic richness & 1.9 & 2.3 & 2.4 \\
\hline Private alleles & 1.9 & 0.2 & 0.3 \\
\hline \multicolumn{4}{|l|}{ Locus A79 } \\
\hline Allelic richness & 5.6 & 4.0 & 4.4 \\
\hline Private alleles & 5.6 & 1.4 & 1.8 \\
\hline \multicolumn{4}{|l|}{ Locus A88 } \\
\hline Allelic richness & 2.6 & 2.0 & 2.0 \\
\hline Private alleles & 2.6 & 0.0 & 0.0 \\
\hline \multicolumn{4}{|l|}{ Locus A107 } \\
\hline Allelic richness & 5.8 & 4.5 & 5.5 \\
\hline Private alleles & 1.6 & 0.7 & 1.2 \\
\hline \multicolumn{4}{|l|}{ Locus Ap43 } \\
\hline Allelic richness & 3.1 & 4.6 & 5.3 \\
\hline Private alleles & 3.1 & 1.0 & 1.6 \\
\hline \multicolumn{4}{|l|}{ Locus Ap66 } \\
\hline Allelic richness & 2.3 & 3.3 & 2.0 \\
\hline Private alleles & 2.3 & 1.8 & 0.5 \\
\hline \multicolumn{4}{|l|}{ Locus Ap81 } \\
\hline Allelic richness & 2.3 & 2.5 & 2.9 \\
\hline Private alleles & 2.3 & 0.5 & 0.9 \\
\hline \multicolumn{4}{|l|}{ Locus AC006 } \\
\hline Allelic richness & 3.1 & 0.0 & 2.0 \\
\hline Private alleles & 0.0 & 0.0 & 0.0 \\
\hline \multicolumn{4}{|l|}{ Locus B124 } \\
\hline Allelic richness & 5.5 & 2.2 & 2.0 \\
\hline Private alleles & 5.5 & 0.2 & 0.0 \\
\hline \multicolumn{4}{|l|}{ Locus HB-THE-03 } \\
\hline Allelic richness & 5.4 & 3.6 & 2.3 \\
\hline Private alleles & 5.4 & 1.4 & 0.1 \\
\hline \multicolumn{4}{|l|}{ Locus HB-THE-04 } \\
\hline Allelic richness & 3.0 & 4.2 & 2.5 \\
\hline Private alleles & 3.0 & 2.4 & 0.7 \\
\hline \multicolumn{4}{|l|}{ AVERAGE } \\
\hline Allelic richness & 3.7 & 4.2 & 3.0 \\
\hline Private alleles & 2.8 & 0.8 & 0.7 \\
\hline
\end{tabular}

\section{DISCUSSION}

Our results indicate that the population of wild European honeybee colonies living in and around the Arnot Forest is almost certainly self-sustaining, that is, it is not being maintained by a heavy influx of swarms from beekeepers' colonies. There are two lines of evidence. The first is simply 
Table III. Summary of the $\mathrm{F}_{\mathrm{st}}$ values for the four independent analyses, each of which is based on one worker bee from each of the 10 colonies in each of the three groups: Arnot Forest, apiary 1, and apiary 2.

\begin{tabular}{llll}
\hline Sample group & Arnot Forest-apiary 1 & Arnot Forest-apiary 2 & Apiary 1-apiary 2 \\
\hline 1 & 0.016 & 0.048 & 0.099 \\
2 & 0.016 & 0.022 & 0.053 \\
3 & 0.027 & 0.069 & 0.086 \\
4 & 0.020 & 0.025 & 0.034 \\
Mean & 0.020 & 0.041 & 0.068 \\
$P$ & $<0.01$ & $<0.07$ & $<0.04$ \\
\hline
\end{tabular}

$P$ values denote probability of significant difference from 0.00

that there are relatively few managed colonies producing swarms in and around the Arnot Forest. Our estimate of the density of wild colonies in this area is 1 colony $/ \mathrm{km}^{2}$, so we estimate that in the summer of 2011 , within the $200-\mathrm{km}^{2}$ study area, there were approximately 200 wild colonies and only approximately 40 managed colonies (in apiary 1 and 2), so only about 40/ $240=17 \%$ of the colonies in the study area were managed colonies. Even this low percentage is rather misleading, however, because the 22 colonies in apiary 1 were not long-term residents of the study area. This apiary was established in spring 2011 and then was removed in fall 2011 after suffering damage by black bears (Ursus americanus). If the managed colonies in apiary 1 are excluded, to make a better estimate of the typical proportion of managed colonies in the study area, then this figure drops to $20 /$ $220=9 \%$. It is likely, therefore, that managed colonies produce only a small minority of the swarms that arise each year in the study area. The second line of evidence is even more telling: We found substantial genetic differences between the colonies in the Arnot Forest colonies and the colonies in both apiaries nearby. This shows that there has been little genetic input from the managed colonies outside the Arnot Forest to the wild colonies inside the Arnot Forest.

Knowing that the wild colonies of honeybees living in and around the Arnot Forest can survive on their own makes them attractive subjects for investigating how honeybees can achieve a stable coexistence with their parasites and pathogens.
Solving this mystery is important because at present, most beekeepers in Europe and North America rely on treating their bees with antibiotics and pesticides. This approach, however, is not sustainable for it leads to the evolution of resistance by the parasites and pathogens (Evans 2003), can lead to contamination of the honey crop (Karazafiris et al. 2008), and can have negative effects on the bees themselves (Burley et al. 2008).

The survival of the honeybee colonies living in and around the Arnot Forest may reflect strong natural selection for disease-resistant bees in these colonies, or strong natural selection for avirulent mites and viruses within these colonies, or both. Strong selection for resistance and avirulence is more likely for colonies living in nature versus in apiculture. Colonies living in the wild rely on their inherent abilities to resist diseases, which drive selection for disease resistance, whereas colonies kept by beekeepers often receive antibiotic or pesticide treatments, which blunt selection for disease resistance. Also, colonies living in the wild are dispersed over the landscape, whereas colonies managed by beekeepers are crowded in apiaries. When colonies are widely separated, their parasites and pathogens are probably transmitted mostly vertically (from parent colony to offspring colony) through swarming, but when living side by side in apiaries, their disease agents are easily transmitted horizontally (between unrelated colonies) through drifting and robbing behaviors (Pfeiffer and Crailsheim 1998; Seeley and Smith in press). Therefore, when honeybee colonies live under natural conditions, it is likely that 
their parasites and pathogens will be selected to be avirulent, for this will enable their hosts to stay healthy and produce the swarms needed to transmit the parasites and pathogens to new colonies (Fries and Camazine 2001; SchmidHempel 2011).

Artificial selection among managed colonies of honeybees has produced honeybees with some V. destructor tolerance (Büchler et al. 2010; Rinderer et al. 2010), but what has natural selection among colonies living in the wild achieved? Studies of two survivor populations of honeybees in Sweden and France have revealed that in both populations, the mite reproductive success (i.e., the proportion of successfully reproducing Varroa mites) is about $30 \%$ lower in wild colonies relative to managed colonies (Locke and Fries 2011; Locke et al. 2012). Curiously, no evidence was found of increased mite removal from adult bees by grooming, which is an important mechanism of mite control in colonies of Apis cerana, the natural host of $V$. destructor (Peng et al. 1987). It remains unclear, however, whether the lower mite reproductive success in the wild colonies in Sweden and France is due to higher resistance by the bees, to lower virulence by the mites, or both. It also remains unknown whether increased resistance to $V$. destructor or decreased virulence of these mites, or both, exists in the bees and mites living in the Arnot Forest.

Besides genetic factors that may be favoring the health of the wild honeybee colonies living in and around the Arnot Forest, environmental factors may also be helping these colonies survive without receiving treatments for $V$. destructor. For example, wild honeybee colonies living in the forests around Ithaca, NY, occupy nest cavities that are only $25-50 \%$ as spacious as beekeepers' hives (Seeley and Morse 1976). Therefore, the size of the nest and the numbers of adult bees, worker brood, and drone brood are all much smaller in wild colonies than in managed ones. Because mites reproduce in cells of brood, and do so preferentially in drone brood (Fuchs 1990), the fewer cells of brood in wild colonies may limit the mite populations in these colonies by giving the mites fewer reproductive opportunities. This may explain a striking feature of the survivor colonies on the island of Gotland in Sweden: the amounts of worker brood and drone brood in these Varroa tolerant colonies are only about one half and one tenth, respectively, of the amounts found in control colonies (Varroa -susceptible colonies typical of what are kept by Swedish beekeepers (Locke and Fries 2011)). Another consequence of wild colonies occupying small nest cavities is a high rate of colony swarming, which could also limit the growth of $V$. destructor populations in these colonies. When a colony casts a swarm, it loses $40-70 \%$ of its worker bee population (Wilde et al. 2005; Rangel and Seeley 2012), and since approximately $50 \%$ of the mites in a colony are on the adult bees (Fuchs 1985), this means that a colony sheds $20-35 \%$ of its adult mites each time it swarms (as shown by Wilde et al. (2005)). And, because a swarming colony can cast multiple swarms - one "prime swarm" and sometimes several "afterswarms" (Gilley and Tarpy 2005) — swarming can quickly reduce a colony's mite population. Besides quickly exporting many mites from a colony, swarming might also give rise to a period of intensive mite removal because swarming creates a period lasting 1-3 weeks when there is no sealed brood in a colony. This period without sealed brood arises because whenever a colony swarms, and the mother queen leaves, it takes the replacement queen 1-3 weeks to emerge as an adult, kill her rivals, get mated, and begin laying eggs. During this period, without sealed (pupal) brood, the mites can neither reproduce nor hide in cells containing pupae, so they suffer a decreased birth rate and perhaps also an increased death rate, being vulnerable to getting bitten by bees and groomed off them (Arechavaleta-Velasco and Guzmán-Novoa 2001).

It is now clear that the population of wild honeybee colonies living in and around the Arnot Forest is surviving without a large immigration of swarms that have escaped from beekeepers' hives, even though this population of wild colonies is infected with the ectoparasitic mite $V$. destructor that arrived in this region of New York State in the mid-1990s (Seeley 2007). It is also now clear that the population of wild colonies living in and around the Arnot Forest is not an "original" surviving population. The first subspecies of Apis mellifera that was introduced to eastern North America was the Dark European 
honeybee, A. m. mellifera, which is native to all Europe north of the Alps (Ruttner et al. 1990). Starting in the 1600s, swarms of this subspecies escaped from the hives of English settlers and established a large population of wild colonies in what are now the eastern states of the USA (Sheppard 1989). We wondered, therefore, if the Arnot Forest bees might show genetic ancestry tracing back to A. m. mellifera. Our autosomal analyses show genetic differences between the wild and managed colonies within the study area, but our mitotyping analysis suggests that the population of wild colonies contains little genetic material from A. m. mellifera (M haplotype) but much from A. m. ligustica and A. m. carnica (both $\mathrm{C}$ haplotype).

The results of the present study show that a population of wild honeybee colonies with European heritage living in North America is self-sustaining despite living on its own. This finding is relevant to the problem of declining numbers of managed honeybee colonies in Europe and North America. The contrast between the stability of this population of wild colonies and the declines in the populations of managed colonies suggests that current apicultural practices are contributing to the losses of managed colonies, perhaps by helping perpetuate the spread of lethal viruses vectored by virulent Varroa mites. What apicultural practices might be causing harm? We suggest that the following four are important: (1) giving colonies mite-control treatments, so there is little or no selection for mite-resistant bees; (2) crowding colonies together in apiaries, so that horizontal transmission of diseases is favored; (3) managing colonies to be unnaturally large, so that they have high honey production and low swarming rates; and (4) moving colonies from place to place, so that there is both strong gene flow that prevents natural selection from altering local allele frequencies in a closed population, and rapid spread of pathogens. By following these apicultural practices, beekeepers are probably hampering natural selection for increased disease resistance by the bees and for decreased virulence by the mites and viruses, and they are probably creating colonies that are bonanza hosts for Varroa mites and the viruses they vector. Beekeepers are probably also hampering the genetic adaptation of bees to the climate and seasons of the local environment, and in this way are probably further hindering colony vitality (Hatjima et al. 2014). More work is needed to test these ideas, but it now seems likely that if a closed population of honeybee colonies is left alone and allowed to live naturally, then it will evolve a balanced relationship with its agents of disease, and its environment as a whole.

\section{ACKNOWLEDGMENTS}

We thank Prof. Peter Smallidge, Director of the Arnot Forest, for permission to study the wild honeybee colonies living in this forest, and Mr. Alan Tremblay, owner of Tremblay Apiaries, for permission to collect samples of bees from two of his apiaries. This research was supported by a Honey Bee Health grant from the North American Pollinator Protection Campaign.

Une population relictuelle des colonies sauvages de l'abeille européenne dans le nord-est des Etats-Unis: étude de sa structure génétique

co-évolution hôte-parasite / avirulence / population relictuelle / abeilles sauvages / forêt d'Arnot

Eine Untersuchung zur genetischen Struktur einer Population wilder Europäischer Honigbienen, die im Nordosten der Vereinigten Staaten überlebte

Wirt-Parasiten-Koevolution / Avirulenz / überlebende Population / wilde Honigbienen / Arnot Forest

\section{REFERENCES}

Arechavaleta-Velasco, M.E., Guzmán-Novoa, E. (2001) Relative effect of four characteristics that restrain the population growth of the mite Varroa destructor in honey bee (Apis mellifera) colonies. Apidologie 32, 157-174

Belkhir, K.P., Borsa, P., Chikhi, L., Raufaste, N., Bonhomme, F. (2002) Genetix 4.04, logiciel sous windows TM pour la genetic des populations. Laboratoire Génome, Populations, Interactions, Université de Montpellier, France

Büchler, R., Berg, S., Le Conte, Y. (2010) Breeding for resistance to Varroa destructor in Europe. Apidologie 41, 393-408 
Burley, L.M., Fell, R.D., Saacke, R.G. (2008) Survival of honey bee (Hymenoptera: Apidae) spermatozoa incubated at room temperature from drones exposed to miticides. J. Econ. Entomol. 101, 1081-1087

Estoup, A., Garnery, L., Solignac, M., Cornuet, J.-M. (1995) Microsatellite variation in honey bee (Apis mellifera L.) populations: hierarchical genetic structure and test of the infinite allele and stepwise mutation models. Genetics 140, 679-695

Evans, J.D. (2003) Diverse origins of tetracycline resistance in the honey bee bacterial pathogen Paenibacillus larvae. J. Invertebr. Pathol. 83, 46-50

Fries, I., Camazine, S. (2001) Implications of vertical and horizontal pathogen transmission for honey bee epidemiology. Apidologie 32, 199-214

Fries, I., Imdorf, A., Rosenkranz, P. (2006) Survival of mite infested (Varroa destructor) honey bee (Apis mellifera) colonies in a Nordic climate. Apidologie 37, 564-570

Fuchs, S. (1985) Untersuchungen zur quantitativen Abschätzung des Befalls von Bienenvölkern mit Varroa jacobsoni Oudemans und zur Verteilung des Parasiten im Bienenvolk. Apidologie 16, 343-368

Fuchs, S. (1990) Preference for drone brood cells by Varroa jacobsoni Oud. in colonies of Apis mellifera carnica . Apidologie 21, 193-199

Galton, D.R. (1971) Survey of a thousand years of beekeeping in Russia. Bee Research Association, London

Garnery, L., Cornuet, J.-M., Solignac, M. (1992) Evolutionary history of the honey bee Apis mellifera inferred from mitochondrial DNA analysis. Mol. Ecol. 1, 145-154

Gilley, D.C., Tarpy, D.R. (2005) Three mechanisms of queen elimination in swarming honey bee colonies. Apidologie 36, 461-474

Goudet, J. (2001) FSTAT Version 2.9.3: a program to estimate and test gene diversities and fixation indices. Institute of Ecology, University of Lausanne. Available at: http://www2.unil.ch/popgen/softwares/fstat.htm. Accessed 8 July 2014

Hatjima, F., et al. (2014) Population dynamics of European honey bee genotypes under different environmental conditions. J. Apic. Res. 53, 233-247

Jaffé, R., Dietemann, V., Allsopp, M.H., Costa, C., Crewe, R.M., Dall'Olio, R., De la Rúa, P., El-Niweiri, M.A.A., Fries, I., Kezic, N., et al. (2009) Estimating the density of honeybee colonies across their natural range to fill the gap in pollinator decline censuses. Conserv. Biol. 24, 583-593

Kalinowski, S.T. (2005) HP-Rare 1.0: a computer program for performing rarefaction on measures of allelic diversity. Mol. Ecol. Notes 5, 187-189

Karazafiris, E., Tananaki, C., Menkissoglu-Spirondi, U., Thrasyvoulon, A. (2008) Residue distribution of the acaracide coumaphos in honey following application of a new slow-release formulation. Pest Manag. Sci. 64, 165-171

Korpela, S., Aarhus, A., Fries, I., Hansen, H. (1992) Varroa jacobsoni Oud. in cold climates: population growth, winter mortality and influence on survival of honey bee colonies. J. Apic. Res. 31, 157-164

Kraus, B., Page Jr., R.E. (1995a) Population growth of Varroa jacobsoni Oud. in Mediterranean climates of California. Apidologie 26, 149-157

Kraus, B., Page Jr., R.E. (1995b) Effect of Varroa jacobsoni (Mesostigmata: Varroidae) on feral Apis mellifera (Hymenoptera: Apidae) in California. Environ. Entomol. 24, 1473-1480

Le Conte, Y., de Vaublanc, G., Crauser, D., Jeanne, F., Rousselle, J.-C., Bécard, J.-M. (2007) Honey bee colonies that have survived Varroa destructor. Apidologie 38, 566-572

Lindauer, M. (1955) Schwarmbienen auf Wohnungssuche. Z. vergl. Physiol. 37, 263-324

Locke, B., Fries, I. (2011) Characteristics of honey bee colonies (Apis mellifera) in Sweden surviving Varroa destructor infestation. Apidologie 42, 533-542

Locke, B., LeConte, Y., Crauser, D., Fries, I. (2012) Host adaptations reduce the reproductive success of Varroa destructor in two distinct European honey bee populations. Ecol. Evol. 2, 1144-1150

Loper, G.M., Sammataro, D., Finley, J., Cole, J. (2006) Feral honey bees in southern Arizona 10 years after Varroa infestation. Am. Bee J. 146, 521-524

Moritz, R.F.A., Kraus, B., Kryger, B., Crewe, R.M. (2007) The size of wild honey bee populations (Apis mellifera) and its implications for the conservation of honeybees. J. Insect Conserv. 11, 391-397

Odell, A.L., Lassoie, J.P., Morrow, R.W. (1980) A history of Cornell University's Arnot Forest. Dept. of Natural Resources Research and Extension Ser. 14, 1-53. [online] http://www2.dnr.cornell.edu/arnot/about/ history.htm. Accessed 15 Dec 2014

Oleksa, A., Gawronski, R., Tofilski, A. (2013) Rural avenues as a refuge for feral honey bee population. $\mathrm{J}$. Insect Conserv. 17, 465-472

Peng, Y.S., Fang, Y., Xu, S., Ge, L. (1987) The resistance mechanism of the Asian honey bee, Apis cerana Fabr., to an ectoparasitic mite, Varroa jacobsoni Oudemans. J. Invertebr. Pathol. 49, 54-60

Pfeiffer, K.J., Crailsheim, K. (1998) Drifting of honeybees. Insect. Soc. 45, 151-167

Potts, S.G., Roberts, S.P.M., Dean, R., Marris, G., Brown, M.A., Jones, R., Neumann, P., Settele, J. (2010) Declines of managed honey bees and beekeepers in Europe. J. Apic. Res. 49, 15-22

Rangel, J., Seeley, T.D. (2012) Colony fissioning in honey bees: size and significance of the swarm fraction. Insect. Soc. 59, 453-462

Raymond, M., Rousset, F. (1995) An exact test for population differentiation. Evolution 49, 1280-1283

Rinderer, T.E., de Guzman, L.I., Delatte, G.T., Stelzer, J.A., Lancaster, V.A., Kuznetsov, V., Beaman, L. (2001) Resistance to the parasitic mite Varroa destructor in honey bees from far-eastern Russia. Apidologie 32, 381-394 
Rinderer, T.E., Harris, J.W., Hunt, G.J., de Guzman, L.I. (2010) Breeding for resistance to Varroa destructor in North America. Apidologie 41, 409-424

Rousset, F. (2008) GENEPOP '007: a complete reimplementation of the GENEPOP software for Windows and Linux. Mol. Ecol. Resour. 8, 103-106

Ruttner, H., Ruttner, F. (1966) Untersuchungen über die Flugaktivität und das Paarungsverhalten der Drohnen. 3. Flugweite und Flugrichtung der Drohnen. Z. Bienenforschung 8, 332-354

Ruttner, H., Ruttner, F. (1972) Untersuchungen über die Flugaktivität und das Paarungsverhalten der Drohnen. V. Drohnensammelplätze und Paarungsdistanz. Apidologie 3, 203-232

Ruttner, F., Milner E., Dews, J.E. (1990) The dark european honeybee, Apis mellifera mellifera Linnaeus 1758. British Isles Bee Breeders Association

Schmid-Hempel, P. (2011) Evolutionary parasitology. Oxford University Press, Oxford

Seeley, T.D. (2007) Honey bees of the Arnot Forest: a population of feral colonies persisting with Varroa destructor in the northeastern United States. Apidologie 38, 19-29

Seeley, T.D., Morse, R.A. (1976) The nest of the honey bee (Apis mellifera). Insect. Soc. 23, 495-512

Seeley, T.D., Morse, R.A. (1977) Dispersal behavior of honey bee swarms. Psyche 94, 199-209
Seeley, T.D., Smith, M.L. (in press) Crowding honeybee colonies in apiaries can increase their vulnerability to the deadly ectoparasite Varroa destructor. Apidologie

Shaibi, T., Lattorff, H.M.G., Moritz, R.F.A. (2008) A microsatellite DNA toolkit for studying population structure in Apis mellifera . Mol. Ecol. Resour. 8, 1034-1036

Sheppard, W.S. (1989) A history of the introduction of honey bee races into the United States. Am. Bee J. 129 (617-619), 664-666

Solignac, M., Vautrin, D., Loiseau, A., Mougel, F., Baudry, E., Estoup, A., Garnery, L., Haberl, M., Cornuet, J.-M. (2003) Five hundred and fifty microsatellite markers for the study of the honeybee (Apis mellifera L.) genome. Mol. Ecol. Notes 3, 307-311

Villa, J.D., Bustamante, D.M., Dunkley, J.P., Escobar, L.A. (2008) Changes in honey bee (Hymenoptera: Apidae) colony swarming and survival pre- and postarrival of Varroa destructor (Mesostigmata: Varroidae) in Louisiana. Ann. Entomol. Soc. Am. 101, 867-871

Visscher, P.K., Seeley, T.D. (1982) Foraging strategy of honeybee colonies in a temperate deciduous forest. Ecology 63, 1790-1801

Visscher, P.K., Seeley, T.D. (1989) Bee-lining as a research technique in ecological studies of honey bees. Am. Bee J. 129, 536-539

Wilde, J., Fuchs, S., Bratkowski, J., Siuda, M. (2005) Distribution of Varroa destructor between swarms and colonies. J. Apic. Res. 44, 190-194 